\title{
Exploration of Application of Confucian Conception of Critical Thinking in Teaching English as a Foreign Language in China
}

\author{
Xuejuan Gong ${ }^{1,2}$ \\ ${ }^{1}$ Wuhan Radio and Television Station, Wuhan, P. R. C \\ ${ }^{2}$ Cook School of Intercultural Studies, Biola University, La Mirada, U.S.A
}

\section{Email address:}

Xuejuan_69@163.com

\section{To cite this article:}

Xuejuan Gong. Exploration of Application of Confucian Conception of Critical Thinking in Teaching English as a Foreign Language in China. International Journal of Literature and Arts. Special Issue: Humanity and Science: China's Intercultural Communication with the Outside World in the New Era. Vol. 8, No. 3, 2020, pp. 134-141. doi: 10.11648/j.ijla.20200803.15

Received: February 27, 2020; Accepted: March 11, 2020; Published: April 14, 2020

\begin{abstract}
Over the past years, fostering critical thinking abilities has become one of the priorities in education in China. So far, much research has been conducted to explore how to resort to Western critical thinking methods to cultivate critical thinking abilities among Chinese students. Meanwhile, among much research in incorporating Confucian educational thought into current English teaching in China, little research has been done to explore the possibility of rendering Confucian conception of critical thinking to this endeavor. This paper argues that Confucian conception of critical thinking possesses similar complementary components to those of the Western conception of critical thinking. Through literature review and text analysis, this paper reviews the Confucian conception of critical thinking and the socio-cultural background that impact its development. Reflection on a case study and field observation shows that Confucian "enlightening approach" works effectively in today's effort in critical thinking cultivation in English teaching; Confucius' description of five-phase comprehensive learning process could be materialized in English teaching to progress from lower level learning (knowledge, comprehension, application) towards higher level learning (analysis, synthesis, and evaluation); Confucian conception of critical thinking, described as "contextual critique' by some Western scholar, could complement Western critical thinking in a positive way. The paper suggests in-depth research in constructing the theoretical framework for the Confucian conception of critical thinking, investigation of other approaches to foster critical thinking abilities besides the "enlightening approach," and thorough studies of current empirical research on critical thinking in TEFL in China so as to see how they can be applied in materializing Confucian conception of critical thinking.
\end{abstract}

Keywords: Confucian Educational Thought, Confucian Conception of Critical Thinking, Western Conception of Critical Thinking, TEFL, Bloom's Taxonomy

\section{Introduction}

Confucius, a great thinker and educator in ancient China, has made lasting impact on teaching and learning in China and other East Asian countries. Centered on a main concern of "how we learn to be human" and principles of "building on the old knowledge for new knowledge, cultivating oneself through self-reflection, practicing and refining what they have learned" [1], Confucian education tradition capitalizes on a "holistic, broad-based and integrated curriculum" [2].

According to House et al, East Asian countries (also known as the Confucian Asian countries) including China, and South Korea have been deeply influenced by Confucian educational philosophies [3]. Li found in her comparative study, in terms of purpose of learning among Chinese students, "ideas in this (Chinese) group (the heart and mind for wanting to learn, diligence, hardship, steadfastness, concentration, humility, the desire) are central to Confucianism, which regards to learning as the only pathway toward the highest goal of life: self-perfection" [4]. Kim proposed "Confucian pedagogic cultures" concluding that, "Despite variations among them, these cultures share the 
following primary pedagogic patterns: a premium placed on education, high social status of, and respect for, the teacher, student attention and discipline in class, mastery of foundational knowledge, and repeated practice" [2]. Besides, Marginson observed the dynamic educational system operated in Asia as the "Confucian Model" which serves as an edge for Asian universities to compete with Western universities and offers a unique model for the universities in the world.

"It rests on four interdependent elements: (1) strong nation-state shaping of structures, funding and priorities; (2) a tendency to universal tertiary participation, partly financed by growing levels of household funding of tuition, sustained by a private duty to invest in education grounded in Confucian values; (3) 'one chance' national examination that mediate social competition and university hierarchy and focus family commitments to education; (4) accelerated public investment in research and 'world-class' universities" [5].

Over the past years, scholars at home and abroad have conducted ongoing research in Confucian educational thought and its relevance to today's education. Meanwhile, an increasing research in incorporating Confucian educational thought into current teaching has been done in China. As Wei found, much study has centered on Confucius' moral education and 129 articles were located in the CNKI database on the topic of teaching students in accordance with their aptitude and English teaching. In his thesis, Wei shared a case study of a college English teacher who assigned reflection paper for the students as a way to live out the Confucian conception of critical thinking, as Confucius said in Analects, "Learning without reflection will end up in confusion; reflection without learning will end up in peril." As Wei saw it, Confucius stressed that learning and reflection should work together for the best outcome [6].

Wei's exploration of Confucian conception of critical thinking in today's English teaching seemed outnumbered by the many studies on "critical thinking and English teaching." Lei recalled that initial effort to create awareness of critical thinking in China started with Prof. Huang Yuansheng who noticed "The absence of Critical Thinking" in 1998, and Prof. Wen Qiufang who researched "The cultivation of critical thinking in oral English teaching" in 1999. When Lei entered the key words of "critical thinking" "English" into CNKI Database in 2017, she found 818 related papers in various periodicals in China within five years from 2013-2017, among which, 22 papers published in core journals of the foreign language category have conducted theoretical and empirical research, and research in training models on the subject. Till today, however, there is no clear theory and operation method in developing critical skills in China's current foreign language teaching [7]. Ma conducted research in the hot issues concerning critical thinking teaching in China based on research paper published in core foreign language journals from CNKI database between 2006 and 2017, finding that "content-based teaching mode, classroom questioning, argumentative discourse analysis, critical thinking assessment, the application of information technology" were listed as the five aspects of the hot issues [8]. As indicated above, none of them touched upon Confucian conception of critical thinking. In other words, so far, Chinese English teachers and scholars, in their effort to foster critical thinking skills among Chinese students, have looked more to Western conception and practice of critical thinking rather than the indigenous Confucian conception of critical thinking. Why?

The first response to this question seems to be the controversy over Confucian education tradition in regards to whether it helps or hinders critical thinking. For a better understanding, the rest of the paper reviews the socialpolitical-cultural impacts on Confucian education thought and its conception of critical thinking; the essence of Confucian conception of critical thinking, and its compatibility and comparison with Western conception of critical thinking; critical thinking and TEFL in China; and implication of Confucian conception of critical thinking for TEFL in China after the examination of literature review, a case study and a field observation.

\section{Development of Confucian and Western Critical Thinking and Their Impact on TEFL in China}

\subsection{The Confucian Conception of Critical Thinking}

By studying the Analects and Xueji, Tan concluded that,

"Critical thinking, interpreted broadly as skillful, reflective and responsible thinking that facilitates judgement is an integral component of Confucian education. Similarly, Xueji enhances the students' critical thinking capacities through approaches such as asking and responding to questions, engaging in reflective discussions and forming one's own conclusions" [2].

Berthal pointed out, besides making connections between knowledge and practice, Confucius also encouraged his students to embrace people from different backgrounds.

"A person may be able to recite the three hundred poems, but if he is unable to put (this knowledge) to full use when he is given a political assignment, or if he is unable to hold his worn in a diplomatic exchange when he is sent abroad on a mission, no matter how many poems he has learned, what good will it do?" (Analects 13:5).

Here, Berthel found the component of critical thinking embedded in Confucianism the same way it is in liberal ideals for education.

"Central to the liberal education mission is the notion that genuinely valuable learning is not characterized by the memorization of a body of information but rather necessarily entails an ability to respond intuitively and appropriately to myriad situations, engage meaningfully with those around us, and cultivate the wherewithal to interact peacefully and productively with all" [9].

Through careful text analysis, $\mathrm{Wu}$ found the following 
traits of an ideal learner in the Confucian education tradition that resemble those of a critical thinker.

An ideal learner is all ears and eyes for new information and is discerning about them, as Confucius says, "I use my ears widely and follow what is good in what I have heard; I use my eyes widely and retain what I have seen in my mind. Knowledge will follow if we consistently do it" (Analects 7:27). An ideal learner is also keenly aware of lifelong learning and daily improvement, as Confucius says, "If you can improve yourself in a day, do so each day, forever building on improvement" (The Great Learning 3:8).

An ideal learner should be discerning about the influence others exert on him in terms of judgment and decisionmaking, as Confucius says, "when walking in a group of three, my teachers are always present. I draw out what is good in them so as to emulate it myself, and what is not good in them so as to alter it in myself" (Analects 7:22); and, "Meet the virtuous and think how to be their match. Meet those not virtuous and use it for self-evaluation" (Analects 4:17).

An ideal learner should be self-reflective and empathetic in study, interpersonal relationship and business, as Zengzi, a disciple of Confucius, says, "Each day I reflect on myself upon three points. In transacting business for others, whether I have been faithful or not? In intercourse with friends, whether I have been sincere or not? And whether I have mastered and practiced the instructions of my teacher or not? (Analects 1:3).

An ideal learner should also be brave to admit mistakes and correct them, as Confucius says, "Having made a mistake and not correcting it, is another mistake itself" (Analects 15:29).

An ideal learner can embrace new knowledge openly, nonjudgmentally yet carefully before he puts it into practice and develop wisdom from it, when Confucius says, "Listen extensively to what people say and cast away doubts, repeat those that you do not doubt with caution and you will make fewer mistakes. Observe extensively how people do things and cast away those you feel uneasy, put the rest into practice with caution and you will have few regrets" (Analects 2:18).

In summary, Wu concluded that ultimately, the purpose of Confucian education is to foster a student to become a junzi, the exemplary person depicted in Confucian classics. A junzi should always be 1) open to new knowledge and good at making connections between old and new information; 2) self-aware, self-reflective, and empathetic; 3) able to conduct analysis and recognize truth from false information; 4) able to consider information from multiple sources; 5) dare to doubt authority and draw accurate conclusions; and 6) good at doing evaluations to correct mistakes. Accordingly, an ideal person in Confucianism is essentially a critical thinker who can "identify its strengths and weakness and recast it in improved form" [10].

Sigurðsson coined the term of "transformative self-critical attitude" found in Confucian critical thinking as something neglected in the contemporary West.

"Thus, Confucius and his followers certainly encourage critical thinking in much the same sense as we find in the West, but they empathize the importance of what may be called 'contextual critique' i.e. a critique that takes note of the particular circumstances in each case and the direction in which they are likely to be heading. Since the underlying value of the critique, is not merely 'truth' but 'appropriate solutions', it will tend to take more factors into consideration than does Western critique in most cases. Confucian critique is nuanced and complex, aiming at an advantageous configuration of the interests of all those concerned" [11].

As a Western scholar, Sigurðsson has seen something valuable: the holistic approach, the contextual approach, and the solution-oriented approach reflected in Confucian conception of critical thinking. Through the above study, Confucian conception of critical thinking is expected to be on an equal footing with the Western conception of critical thinking, which makes their meeting and integration possible.

\subsection{The Controversy over Confucian Conception of Critical Thinking}

There have been debates over whether Chinese culture and Confucian education thought facilitates or hinders critical thinking.

\subsubsection{Socio-political Impact}

In his recording of the path of education in ancient China, Reagan observed that, around the age of 7 or 8 , children started to enter a study group where they memorized the Four Books and Five Classics together for the civil service examinations. Until its collapse in 1905, six years before the founding of Republic China in 1911, the examination system has served for the election of officials, as Cleverley argued.

"The imperial civil service examination made it possible for a man from humble origin to move into a position of political power, and it also enabled districts to gain national prominence through their native sons. Because it served the cause of social mobility, it had an integrating and stabilizing effect on Chinese life generally. Further, the infusion of new blood, which the examination process permitted, reduced the political power of the hereditary aristocracy and clans, and strengthened the throne" [12].

But according to Guo, as a result of the thousand-year national examinational system in China, education in China "is still extremely oriented toward rote memorization for tests" [10].

\subsubsection{Cultural Impact}

Wu recorded scholars including O'Sullivan \& Guo, Paton and Zhu who voiced their shared belief that "critical thinking is incompatible with Asian cultures," and Flowerdew who pointed out that Chinese students in the context of Confucian tradition, should not challenge teachers for the sake of face [10]. In addition to the hierarchical structure reflected in teacher-student relationship, group or collectivist conformity mentality also plays out as a cultural factor, as students are generally discouraged to stand out, to question and to challenge. Rajaram found that "power distance, uncertainty 
avoidance and philosophy of Confucianism according to the cultural dimensions proposed by Hofstede" hindered the mainland Chinese students in Singapore in pursuing Westernbased education. As a result, "Lectures emerged as the most perceived effective technique preferred (self-reported by students) when measured across the cultural dimensions of power distance and uncertainty avoidance" [13].

In summary, the above cultural climate is supposed to have produced East Asian students "who, in a traditional Confucian context, are more likely to be diligent yet obedient and lacking critical thinking" as Atkinson, Durkin, Durkin, O'Sullivan \& Guo rightfully noted [10].

Teachers seem to have suffered as well. Sjöström disclosed in his interview the concern from teachers that "Confucian traditions of self-discipline and respect for authority might constrain learners' autonomy, innovative thinking and free expression in the classroom which can limit creativity and scientific development" [14].

Such a seemingly contradicting opinion of Confucian educational tradition somehow parallels to the paradoxical position of Confucianism, "Confucianism used to be condemned as a major cause for the economic stagnation of East Asian countries in the $19^{\text {th }}$ century and then started to be praised as a major constituent in the belated but rapid economic take-off and sustained industrialization process in Japan first, whose path was followed by South Korea, Taiwan, Singapore, Hong Kong, and now China" [5].

Under the push and pull of different factors, Confucian education thought and its conception of critical thinking seems to look like a kaleidoscope from which different people see (choose to see) different things. No wonder Sjöström concluded in his research that, "Confucian values and traditions seem to both hinder and support the science teachers' implementation of inquiry-based and learnercentered approaches" [14].

\subsubsection{Bloom's Taxonomy}

One of the big myths about the two critical thinking patterns evolves around Bloom's taxonomy.

According to Bloom and his associates, this taxonomy comprised six levels, from lower levels to higher levels: "knowledge, comprehension, application, analysis, synthesis, and evaluation. The first three levels are considered lower levels, and the other three levels are seen as higher levels of this taxonomy."

Wang \& Sotrey conducted a study among a group of Chinese English teachers, concluding that, "the findings showed these teachers taught the lower levels of taxonomy, which are characterized by rote learning, memorization, knowledge transmitting, lecture, and focusing on exams. These teaching methods run contrary to Western democratic approaches characterized by negotiating curricular priorities with students, giving out learning contracts instead of exams, and involving students when planning lessons" [15].

However, $\mathrm{Wu}$ challenged this point by referring to Confucius' description of five-phase comprehensive learning process, "The extensive study of what is good, accurate inquiry about it, careful reflection on it, the clear evaluation of it, and the earnest practice of it" (Zhongyong 19).

"Extensive study" is the lowest level of thinking, knowledge, and comprehension. The higher-order thinking skills include "accurate inquiry" and "careful reflection" (analysis and synthesis), then "clear evaluation," followed by 'the earnest practice"(application), and finally creation. These Confucian thoughts encourage people to learn by thinking analytically and critically. These thoughts are definitely consistent with that, least, a critical thinker should be good at conducting analysis, drawing accurate conclusions, and articulating thoughts" [10].

Thus, Wu concluded that, "Confucian critical thinking as a whole is congruent with Bloom's taxonomy of educational objective, highly related to the skills of critical thinking" [10].

So what has prevented the good Confucian critical thinking from playing out in real teaching? Besides the social-cultural factors mentioned above, Zhong summarized, large class sizes, centralized curriculum, the lack of quality English teachers, all posed challenge to the implementation of Confucian critical thinking in English teaching [16].

Here $\mathrm{Wu}$ argued about "the urgent necessity to explore how to properly apply the Confucian view of critical thinking to benefit students' development in both East Asian and Western countries."

"Instead of denying Confucianism, more emphasis should be placed on properly integrating more of the essence of Confucian heritage into the curriculum. On the other hand, critical thinking cannot be separated from basic skills. Higher-order thinking activities are based on mastering fundamental knowledge. Having excellent basic knowledge and skills is an advantage of Chinese students" [10].

\subsection{The Development of Western Critical Thinking}

Ryan \& Louie held, that critical thinking is regarded as the Western or Euro-American thinking with a history of 2,500 years. According to Chaffee, the original meaning of the word "critical" means to discover the essence of things and analyze it. As the father and model of critical thinking, Socrates passed on a critical attitude that people should never take things for granted; instead they should seek truth through evidence collection and reasoning. His legacy was carried on by the Skeptics, and "was reinforced during the Renaissance, Reformation and Enlightenment periods" [11].

Brookfield summarized, "Analytic philosophy and logic, natural sciences, pragmatism, psychoanalysis, and critical theory" as five "critical intellectual traditions." Despite the different traditions, their understanding of critical thinking is common in "to recognize, and question, the assumptions that determine how knowledge in that discipline is recognized as legitimate" [17].

The 1930s witnessed a rise of research interest in critical thinking in America. In 1934, John Dewey defined critical thinking as "reflective thinking" and proposed a model progressing from "suggestion, problem definition, hypothesis generation, reasoning, and hypothesis testing" [10].

During the $1980 \mathrm{~s}$, the cultivation of critical thinking 
abilities has become the center of American educational reform. So far, innovative teaching methods including heuristic education, team projects, jigsaw projects, case studies have facilitated the fostering of critical thinking skills among students.

Since the 1990s, scholars around the world have continued to conduct in-depth study in critical thinking. Ennis expanded critical thinking as "reasonable, reflective thinking that is focused on deciding what to believe or do." Scriven observed that under the influence of postmodernism, critical thinking took on the component of "questioning and challenging the existing knowledge and social habitudes" as essential. Paul \& Elder summarized critical thinking as "the art of thinking in such a way to: 1) identify its (the objective's) strengths and weaknesses, and 2) recast it in improved form (where necessary)" [10].

Today, critical thinking is regarded as an indispensable skill for talents of the $21^{\text {st }}$ century. Sigurðsson noticed the large columns of books that "present themselves as self-helps manuals to train the critical thinking skills of readers (and future leaders)" and thus concluded that critical thinking is "clearly a marketable commodity or an industry in great demand to which these writings are responding" [11].

In such a social context, when it comes to education, critical thinking abilities are highly valued as the higher levels of Bloom's taxonomy.

"Western teachers, whether they are teachers of children or teachers of adults, are encouraged to emphasize the higher levels of Bloom's taxonomy. If students can analyze, synthesize, and evaluate freely what they have learned, they have a good command of the lower levels of this taxonomy. Further, the higher levels of this taxonomy are believed to lead to greater autonomy in thinking. In other words, critical thinking skills are far more important than just mastery of knowledge. Western teachers frown upon those who teach only the lower levels of Bloom's taxonomy" [15].

\subsection{Critical Thinking and TEFL in China}

The research in and practice of cultivating critical thinking skills seem to gather momentum after the official issue of the most recent outline of College Entrance Examinations (Gao Kao) by the Ministry of Education of PRC. "According to the Ministry of Education of China, critical thinking skills are regarded as one of the major components of all examinations across subjects. Students' ability to analyze, suggest, define problems, reason, test hypotheses, interpret, explain, solve problems, and innovate is assessed. Based on how they place in the assessment, students are selected for college admission. Consequently, how to foster students' growth as critical thinkers has become a matter of importance for Chinese educators across the educational spectrum" [10].

In her research, Ma found that the research on critical thinking teaching in foreign languages in China present the following characteristics: first, the research has focused mainly on English majors; second, critical thinking training focuses on integration with foreign language skills training in writing, reading, translation, etc; third, attention is given to critical thinking cultivation through classroom questioning, and argumentation language analysis; fourth, emphasis is placed on mainly using level model of critical thinking competence as theoretical basis; fifth, incorporation of modern educational technology into critical thinking training [8].

Chinese TEFL educators' warm response seem to be wellgrounded, for Chinese English students are always in the business of traveling back and forth between Chinese and English languages, and Chinese and English thinking patterns. According to Zhang, the way and law of human thought must be reflected in language, and the structure and habits of language, to a certain extent, will also work on the way of thinking and habits. English and Chinese are different language systems with quite different language structures. English featuring hypotaxis facilitates a linear thinking, while Chinese featuring parataxis facilitates a circular thinking pattern. Therefore, English learning contains not only the mastering of language knowledge but also the cultivation of another kind of thinking ability [18].

\section{Methods and Results}

As such, teaching English as a foreign language in China sees the meeting of two thinking patterns, including Confucian critical thinking and Western critical thinking. It would be of great value to compare two critical thinking patterns in the process of TEFL to see how they interact for a better learning outcome. Unfortunately, as meaningful and valuable as it seems, so far very few empirical studies have directly concentrated on how to apply Confucian educational principles to enhance critical thinking skills, especially in English teaching. An examination into a case study and a field observation was conducted to explore the possible application of Confucian conception of critical thinking to TEFL in China.

\subsection{Case Study of Critical Thinking Development at the Affiliated Primary School of Huazhong University of Science and Technology (HUST)}

On Jan, 7, 2020, China Education Daily reported the steady progress the Affiliated Primary School of Huazhong University of Science (HUST) has made to incorporate elements of critical thinking in the classes of Chinese, math, and English to help foster critical thinking abilities among students since 2014. As the article reported, as the pioneer of the project, the English department of the school developed a three-step approach of "slowing down" "verification" and "awakening" to facilitate critical thinking among students. "Slowing down" allows in-depth thinking for students to ask questions and to search for answers. Then, they test and verify their ideas or thoughts until finally they are awaken to a new idea or conclusion. The teacher in the process navigated the students along the quest with questions and guidance, a very similar process Confucius enlightened his students. In the "enlightening approach" in Confucian tradition, Confucius said, "I do not enlighten (a person who is) 
not striving (to understand); I do not provide (the words to a person who is) not already struggling to speak. Or I have raised one (corner) and (the person) does not come back with the other three (corners), I will not (teach that person) again (Analects 7:8). According to Tan, Confucius modeled how he as a teacher "fosters reflection and inferential thinking by providing the initial point of learning and expecting the student to make their own deductions and judgements" [2]. This time, the Affiliated Primary School of HUST testified its effectiveness again. Last but not the least, the teachers tried to create an active atmosphere in the class to encourage students to speak up, a favorable environment for critical thinking to blossom [19].

\subsection{Field Observation on Critical Thinking Camp at Step-up Language School}

In January, 2019, Step-up, an American-run language school based in Wuhan, held a one-week critical thinking camp. I was asked to document the event, so I followed them for seven days. 14 Chinese students (9-15 years old) mingled with 6 American students (8-15 years old) in the camp for a very interactive English learning environment. In this oneweek day camp, 20 students were divided into 4 groups following a routine of craft, watching video, group discussion and presentation, all wound up to a big final project called "A Virtual Life." Each day the camp started with a game or craft to help the students break ice and warm up. Then they watched a TEDS talk and discussed about what they heard from the lectures. Then two groups formed one side to take on the other side formed by another two groups, debating on the topic. In the afternoon, they started to work within their groups on the final project. For the final project, each group was asked to discuss their dream life, divide it into different life stages, talk about different challenges they might face and how to overcome the problems. Finally, each group was going to present their dream life with the combination of PPT, videos and stage play. The students went home to do research and talk with their parents, shared their ideas with group members, and worked together. These are my observations:

i. The Chinese students enjoyed the hands-on experience with crafts and games that helped them get a handle of critical thinking. Take the "tower building" for example. Each group was given 20 paper cups and discussed how to build the tower as high as possible and keep it standing as long as possible. The kids discussed and experimented several ways in a given time until they had a final plan to start building. The kids enjoyed the fun process and each member in the group contributed ideas and efforts. Afterwards, each group reflected on what they had done right or wrong in the process and shared them with other groups. Thinking, discussion, testing, creation, and reflection, all the components of critical thinking were covered.

ii. The Chinese students, however, did not feel comfortable challenging their American friends and teachers in projects like debating, despite that they had good ideas and could express them well. After they shared their opinions in the group, they naturally drew back and let their American teammates to speak for them.

iii. Besides being reluctant to challenge, Chinese students seem to be able to accommodate paradoxical thinking well. In face of one problem, they thought hard, thought long and came up with very thorough solutions. They normally said, "On the one hand, I see...; but on the other hand, I think that also has a point." This kind of double mindedness could drive their American friends crazy who insisted on making a point and coming up with one solution.

\section{Discussion}

\subsection{Reflection on the Case Study and Field Observation}

First, Chinese students are capable of filling in the six levels of Bloom's taxonomy of knowledge, comprehension, application, analysis, synthesis, and evaluation after modeling and training. In the above examples. Chinese students caught up with their American counterparts fast when they discussed and analyzed the pros and cons of a construction project, and felt very comfortable evaluating their doing afterwards. Besides, their solid foundation in comprehension and smooth application of their knowledge gave their group an edge in competing with other groups.

Second, critical thinking is culturally situated. In the camp scenario, Chinese students demonstrated different critical thinking orientation than their American counterparts, that they are thorough, solution-based like the 'contextual critique' coined by Sigurðsson [11]. It is easy to see the collectivist traits of group thinking mentality behind the "contextual critique." And they are viewed in a positive light as contributing and communal in the eyes of the Western scholar. After all, not every situation needs just critique. On the other hand, the Chinese came up with solutions, but not much creation as the Chinese do not think out of the box the way their American counterparts do. This also seems to reflect what $\mathrm{Li}$ observed that, "Chinese teachers put more emphasis on fostering students' ability to question and think, so as to cultivate a serious scientific attitude and rigorous scholarship. American university teachers, however, focus more on training students' critical spirit in terms of comprehensive application ability and innovative consciousness" [20]. In the camp case, the Chinese and American students adjusted to each other's critique thinking approaches and worked well together, which gave an encouraging hope for Confucian critical thinking and Western critical thinking to complement each other.

Third, Confucian's enlightenment approach still works very well in facilitating questions and thinking for students.

\subsection{Implications}

The first implication is that, there is great value in understanding and applying Confucian conception of critical thinking in fostering critical thinking abilities among Chinese 
students; and its theoretical framework and empirical work needs further study.

The second implication is that, Confucian conception of critical thinking is compatible with Western conception of critical thinking with the same components of analysis, synthesis and evaluation, and its unique contextual, solutionbased orientation could complement the Western conception of critical thinking.

The third implication is that, reliving approaches and methods in Confucian education tradition for the cultivation of critical thinking skills is of importance, incorporation of other research findings in critical thinking and TEFL is definitely necessary as well, especially in reaching the full capacity of the six levels of Bloom's Taxonomy.

The fourth implication is that, cultural factors are to be considered in contextualizing and integrating Western conception of critical thinking into Confucian conception of critical thinking to produce good outcomes. But culture is fluid, not rigid, especially in the era of globalization. In a study, Kaur \& Noman shared a finding indicated that, "collectivist teachers will embrace individualistic practices of teaching which are congruent with their own cultural beliefs" [21]. So East is meeting the West with infinite possibilities.

The fifth implication is that, critical thinking is both a skill, and an important component of humanity. Confucian education thought, with "to be fully human" as its main concern, could extend rich findings in this area worthy of future research.

\section{Conclusion}

Rediscovering the value of Confucian conception of critical thinking and exploring its application in today's English teaching is more than a sentiment of national pride. It is a natural branch of the big tree of reconsidering Confucian education thought in today's world by many scholars from home and abroad that finally stands on its own for its significance.

This paper has made an effort to explore the sociopolitical-cultural context where the Confucian conception of critical thinking has developed, its essence, its compatibility with the Western conception of critical thinking, and its implication for TEFL in China. Owing to the preliminary status of the research on the topic at this point, the depth of this paper seems to be only theory-based without the gravity of much empirical data to back it up. Other than that I believe strongly Confucian critical thinking deserves more in-depth exploration in TEFL in China. Nonetheless, it is my hope that this endeavor serves as a start. My paper hopes to point to the following directions for more research in the future including: deep examination into what cultural aspects have impacted Confucian critical thinking to what extent, and if there are ways to counterwork those influences; empirical research into the application of Confucian critical thinking in real classroom teaching in general, and in TEFL in particular, and if the two could complement each other; exploration of the condition and outcome of the integration of Western critical thinking and Confucian critical thinking; how Confucian critical thinking plays out in mainland China, Asia, and the world. The above research could be done through comparative study, field research, interview, empirical study, and other qualitative research method.

\section{References}

[1] Kee, Y. (2007). Adult learning from a Confucian way of thinking. In Merriam, S. B., \& Associates. Non-Western perspectives on learning and knowing. Malabar, FL: Krieger Publishing Company. ISBN i-57524-280-X.

[2] Tan, C. (2017). Confucianism and education. In Noblit, G. (Ed.), Oxford Research Encyclopedia of Education (pp. 1-18). New York: Oxford University Press. https://doi.org/10.1093/acrefore/9780190264093.013.226.

[3] House, R. J. m Hanges, P. J. Javidan, M., Dorfman, P, P. W., Gupta, V (2004). Culture, leadership, and organizations: The GLOBE study of 62 societies. Thousand Oaks: Sage Publications.

[4] Li, J. (2003). U.S. and Chinese cultural beliefts about learning. Journal of Educational Psychology, 95 (2), 258-258-267. https://doi.org/10.1037/0022-0663.95.2.258.

[5] Marginson, S. (2011). Higher education in East Asia and Singapore: rise of the Confucian model. Higher Education (00181560), $61 \quad$ (5), $\quad$ 587-587-611. https://doi.org/10/1007/s10734-010-9384-9.

[6] Wei, Zhiguo (2016). The Implications of Confucius Educational Thought for College English Teaching. Retrieved from www.ixueshu.com.

[7] Lei, Chongyan. (2017). A review of critical thinking ability training based on CNKI in recent five years. Yangtze Series. Theoretical Study, 9, 170-171.

[8] Ma, Lihong (2019). Hot issues in critical thinking training in foreign language teaching in China. Journal of Tianjin University of Technology and Education, V0l. 29 No. 1 DOI: 10.19573/j.issn2095-0926.201901016.

[9] Berthal, K. (2017). Creating harmony from diversity: What Confucianism reveals about the true value of liberal education from the $21^{\text {st }}$ century. The ASIANetwork Exchange: A Journal for Asian Studies in the Liberal Arts, 24 (2), 6-6-26. https://doi.org./10.16995/ane.177.

[10] Wu, Yin. (2018). Faciliating critical thinking of Chinese students: a Confucian perspctive. In Liu, Xiufeng., \& Ma, Wen. (2018). Confucianism reconsidered: Insights for American and Chinese education in the twenty-first century. State Univeristy of New York Press. ISBN: 9781438470016 .

[11] Sigurðsson, G. (2017). Transformative critique: what Confucianism can contribute to contemporary education? Studies in Philosophy and Education, 36 (2), 131-131-146. DOI: $10.1007 / \mathrm{s} 11217-015-95023$.

[12] Reagan, T. G. (2018). Non-Western educational traditions: Indigenous approaches to educational thought and practice $\left(4^{\text {th }}\right.$ ed.) New York, NY: Routledge. Kindle Edition. 
[13] Rajaram, K.(2014). East versus west: the descendants of confucianism vs.evidence-based learning mainland Chinese learners in pursuit of western-based edication in Singapore. Journal of education and human development, 3 (1), 239-281. DOI: 10.1109/CICEM.2013.6820141.

[14] Sjöström. J. (2018). Science teacher identity and ecotransformation of science education: comparing Western modernism with Confucianism and reflexive building. Cultural Study of Science Education, 13: 147-161. https://doi.org./10.1007/s11422-016-9802-0.

[15] Wang. Victor C. X. \& Storey. Valerie. A. (2015) Andragogy and Teaching English as a Foreign Language in China, The Reference Librarian, 56: 4, 295-314, DOI: 10.1080/02763877.2015.1057680.

[16] Zhong, Qunyan. (2012). Understanding English Teaching and Learning Context in CHina. Global Education Review, 1 (2). $1-12$.

[17] Brookfield, Stephen D. (2012). Teaching for critical thinking.
Tools and techniques to help students question their assumptions. San Francisco: Jossey-Bass.

[18] Xueli, Zhang. (2010). The enlightment of Confucian educational thoughts on English teaching in China. Journal of Shanxi Normal University. Special Issue for Graduate Studies, Vol. 37. 150-152.

[19] From reflection to critical thinking, retrieved from http://paper.jyb.cn/zgjyb/html/2020-01/07/node_5.htm.

[20] Li, Zhengxuan. (2014). The cultivation of critical thinking in American universities and its enlightment on English teaching in China. Foreign Languages in China. Vol 11. No. 6 (Genral Serial No. 62). 14-20. DOI: 10.13564/j.cnki.issn.1672-9382.2014.06.003.

[21] Kaur, Amrita. \& Noman, Mohammad. (2015). Exploring classroom practices in collectivist cultures through the lens of Hofstede's model. The Qualitative Report. Volume 20, Number 11, Article 5, 1794-1811. 